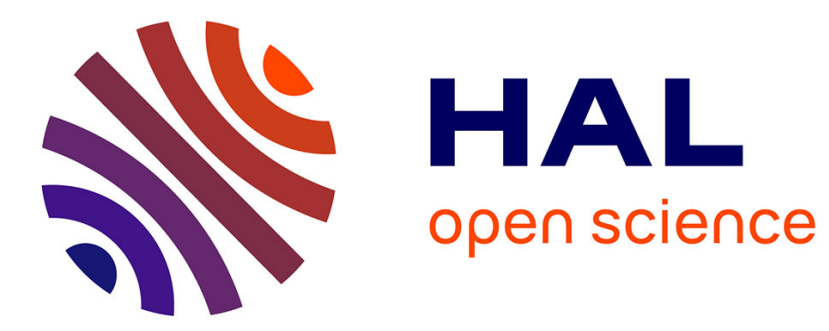

\title{
A methodology for planning and controlling workload in a job-shop: a four-way decision-making problem
}

\author{
Maria Rosário Alves Moreira, Rui Alberto F. S. Alves
}

\section{To cite this version:}

Maria Rosário Alves Moreira, Rui Alberto F. S. Alves. A methodology for planning and controlling workload in a job-shop: a four-way decision-making problem. International Journal of Production Research, 2009, 47 (10), pp.2805-2821. 10.1080/00207540701725083 . hal-00513013

\section{HAL Id: hal-00513013 \\ https://hal.science/hal-00513013}

Submitted on 1 Sep 2010

HAL is a multi-disciplinary open access archive for the deposit and dissemination of scientific research documents, whether they are published or not. The documents may come from teaching and research institutions in France or abroad, or from public or private research centers.
L'archive ouverte pluridisciplinaire HAL, est destinée au dépôt et à la diffusion de documents scientifiques de niveau recherche, publiés ou non, émanant des établissements d'enseignement et de recherche français ou étrangers, des laboratoires publics ou privés. 


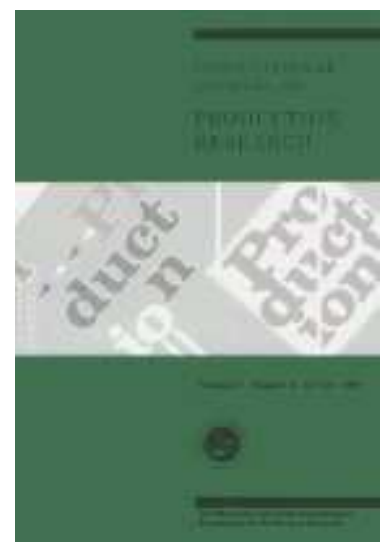

\section{A methodology for planning and controlling workload in a job-shop: a four-way decision-making problem}

\begin{tabular}{|r|l|}
\hline Journal: & International Journal of Production Research \\
\hline Manuscript ID: & TPRS-2007-IJPR-0471.R1 \\
\hline Manuscript Type: & Original Manuscript \\
\hline $\begin{array}{r}\text { Date Submitted by the } \\
\text { Author: }\end{array}$ & 25-Aug-2007 \\
\hline Complete List of Authors: & $\begin{array}{l}\text { Moreira, Maria; University of Porto, Faculty of Economics } \\
\text { Alves, Rui; University of Porto, Faculty of Economics }\end{array}$ \\
\hline Keywords: & JOB SHOP, ORDER RELEASE \\
\hline Keywords (user): & Input-output control, Decision-making \\
\hline
\end{tabular}

\section{s) ScholarONE" \\ Manuscript Central}




\title{
A methodology for planning and controlling workload in a job-shop: a four-way decision-making problem
}

\author{
M. R. A. MOREIRA $\dagger^{*}$ and R. A. F. S. ALVES $\dagger$ \\ $\dagger$ Faculty of Economics, University of Porto, \\ ‡EDGE, University of Porto \\ R. Dr. Roberto Frias, 4200-464 Porto, Portugal \\ Tel.: (351) 225571 100; Fax: (351) 225505050 \\ mrosario@fep.up.pt; ralves@fep.up.pt
}

\begin{abstract}
*Corresponding author:
Maria do Rosário Alves Moreira

Faculty of Economics, University of Porto

R. Dr. Roberto Frias, s/n, 4200-464 Porto, Portugal

Tel.: (351) 225571 100; Fax: (351) 225505050

mrosario@fep.up.pt
\end{abstract}




\title{
A methodology for planning and controlling workload in a job-shop: a four-way decision-making problem
}

\begin{abstract}
There has been extensive research on workload and input-output control with the objective of improving manufacturing operations in job-shops. In this paper, a multiple decision-making scheme is proposed to plan and control operations in a general jobshop, and to improve delivery and workload related performance measures. The jobshop characteristics reinforce the need for designing a global system that controls both the jobs entering (order acceptance, due date setting and job release) and the work-inprocess (dispatching), leading to an improvement of operational measures. Previous research has concentrated on scheduling a set of orders through the shop floor, according to some decision mechanism, in order to optimize some measure of performance (usually total lead time). This means that, since only a part of the decisionmaking system is being optimized, the resulting decision may be sub-optimal. In this paper it is shown that the performance of the different decision rules changes when they are considered simultaneously. Hence, a higher level approach, where the four decisions (order acceptance, due date setting, job release and dispatching) are considered at the same time, should be adopted to improve job-shop operational performance.
\end{abstract}

Keywords: Job-shop; Order release; Input-output control; Decision-making

\section{Introduction}

Workload and input-output control is of crucial importance in make-to-order production environments in order to improve manufacturing operations. Workload control is an approach that attempts to manage manufacturing lead times and is particularly appropriate for job-shops and make-to-order companies. In spite of an early paper 
stating that the input rate of jobs should not exceed the output rate for a manufacturing system (Wight 1970), most research has focused on the development of alternative order release mechanisms. Input-output control has received a lot of attention in the scientific literature in recent years (Kingsman 2000, Oosterman et al. 2000, Haskose et al. 2002, 2004, Henrich et al. 2004, Stevenson 2006, Land 2006, Stevenson and Hendry 2006, to cite only a few of them). Moodie 1999 and Moodie and Bobrowski 1999 looked at the problem of demand management and considered the acceptance and due date assignment decisions. They used simulation to test different demand management bidding and negotiation strategies for various market and firm scenarios.

This paper aims at studying a multiple decision-making scheme for planning and controlling operations in a general job-shop, and for improving delivery and workload related performance measures. The decision-making scheme includes four main decisions: (i) accept, negotiate or reject an in-coming order; (ii) define the order's due date; (iii) release the accepted jobs to the shop floor or keep them in the pre-shop pool; and (iv) dispatch the jobs at the station level. At each decision stage benchmark rules are considered (e.g., total acceptance, immediate release or first-come-first-served dispatching), as well as some rules proposed in previous studies (e.g., acceptance based on total accepted workload or negotiable, backward infinite loading, modified infinite loading, total work content, number of operations, or earliest due date).

Simulation experiments were performed to analyse how the global planning and controlling method works and to compare the rules presented with the benchmark rules with the objective of studying the four dimensional decision problem.

This paper has three main objectives: firstly, to present a scheme for planning and controlling the four decision-making problem, secondly, to explore and understand the 
relationships among these four decisions, analysing the impact on several job-shop performance measures, and thirdly, to identify potential directions for future research.

The paper is structured as follows: the following section presents the main characteristics of the job-shop production process. Then, the multiple decision-making scheme proposed is detailed. In the last two sections the research methodology (simulation model, experimental factors, performance measures and data collection) is outlined, and the results of the main experiment are discussed. The conclusion summarizes the study and presents important observations regarding the results.

\section{The job-shop production process}

The job-shop is one of the most common production processes, found in many manufacturing firms and service companies. A manufacturing job-shop produces many different items, usually in small lots, and different products generally have different routings or sequences of operations. This has a significant impact on shop floor management, and makes it difficult to predict demand (and, therefore, equipment usage) as well as bottleneck sections or machines. As a result, the amount of work-in-process inventory in a job-shop is usually large, as well as the flow time. Since each order may be for a different product, equipment and production process should be flexible. These features reinforce the need for a system that controls the entering jobs (job release) and the in-process stage of the different tasks, in order to estimate, as accurately as possible, deadlines and production costs for the jobs at hand. The problem is made worse because such manufacturing companies often have to compete with each other in order to win customers' orders (Hendry and Kingsman 1989). 
A general model of the shop floor in a job-shop is a network of machines each with a set of jobs waiting their turn to be processed. Haskose et al. 2004 described how a job-shop environment may be modelled as an open queuing network.

\section{The multiple decision-making design}

In a broad sense, the production control system for a job-shop consists of four stages. Associated with each stage is a control decision: $1^{\text {st }}$ ) accept, reject or negotiate an order, $2^{\text {nd }}$ ) define the order's due date, $3^{\text {rd }}$ ) release or not an order to the shop floor and $4^{\text {th }}$ ) define the sequence in which the orders will be processed on the shop floor. The flowchart in Figure 1 shows these four decisions, where they are made and the relationships among them.

\section{[Insert Figure 1 about here]}

It is assumed that orders arrive according to a Poisson process. Besides the widespread use of the Poisson distribution, there is some theoretical evidence that it provides a good approximation for the arrival process (Albin 1982). The routing for each order and the processing time at each station is generated at this stage. The routing is purely random: the number of operations follows a discrete uniform probability distribution between one and six machines. The order has an equal probability of having its first operation in any of the six machines and of going to the other machines, until being completed. After the definition of the job characteristics, the order is placed in a pending (for acceptance) orders file, and the first decision has to be made: to accept or 
to reject (or to negotiate, depending on the decision rule) the order, taking into account information such as price, due date, product specifications, quality levels, shop capacity, etc. In this study the total accepted workload and/or the due date are considered to decide about the acceptance of an order.

The literature on order acceptance/rejection is quite recent. The common assumption is that all orders received by the shop are accepted, regardless of shop conditions or order characteristics. Philipoom and Fry 1992 relaxed this assumption, so that in times of high shop congestion it may be better to reject an order than to accept it and deliver it late. The rationale is that when the shop floor is highly congested, accepting more orders may threaten the ability of the shop to fulfil the other orders' due dates. Wester et al. 1992, Wouters 1997, Nandi and Rogers 2003 and Ebben et al. 2005, Moreira and Alves, 2006 are some of the papers where the possibility of accepting or rejecting is analysed.

The decision about the due date assignment is made simultaneously with the acceptance decision, and a negotiation with the customer may occur. There are several ways to determine the due date; in general, due date rules include information about the order (e.g., number of operations, processing time in each machine, orders arrival date) and about the shop floor (workload in each machine, queues, etc.). There is a lot of research on this issue, alone or combined with other decision rules (e.g. Seidmann and Smith 1981, Panwalkar et al. 1982, Bertrand 1983a, 1983b, Baker 1984, Ragatz and Mabert 1984, Bobrowski and Park 1989, Vig and Dooley 1991, Ahmed and Fisher 1992, Tsai et al. 1997, Sabuncuoglu and Karapinar 2000).

After an order has been accepted, it is placed in an "accepted orders file", or the pre-shop pool file, since it is assumed that materials are available when the job is 
accepted. The order (or job) release decision establishes when a release must occur and which of the jobs eligible for release are actually sent to the shop floor. The releasing function controls the level of work in process inventory. It usually takes into consideration some job features (like expected total processing time, due date, number of operations, routing, etc.) and/or the shop floor congestion (total workload, workload per machine, etc.). Information about the shop capacity is hardly ever considered, notwithstanding the fact that it represents a major element of the input/output control. Several order release mechanisms have been suggested and studied in the literature, and an extensive list can be found in Bergamaschi et al. 1997, Cigolini et al. 1998 or Sabuncuoglu and Karapinar 1999. The release method proposed by Land and Gaalman 1996, 1998 is of particular interest as it emphasises the importance of workload control. More recently, Bertrand and Van de Wakker 2002 investigated the effect of a number of different order release policies. Moreover, emphasis is being placed on integrating the order release mechanism in the planning system.

Once a job is released to the shop floor, it enters the production system and goes to the first machine in its routing sequence. It typically joins a queue of other jobs waiting their turn to be processed, and it is necessary to decide which job will be processed first. This control decision often is referred to as "dispatching". The dispatching decision was one of the first topics to receive a great deal of attention in the operations management literature (Conway 1965, Bulkin et al. 1966, Moodie and Roberts 1968, Panwalkar and Iskander 1977, Graves 1981, Ramasesh 1990 to cite only a few of them). Even today it is a matter of research but, usually, associated with other decisions. Once the work on a job at a machine is completed the job is sent to the next machine, where, again, it joins a queue of jobs waiting to be processed. 
When all processing has been completed, the job is placed in the finished-goods inventory until its delivery (due) date. Early deliveries are forbidden.

\subsection{Accept, negotiate and/or reject decision}

The first decision to be made is when a customer places an order. In this study, three accept/reject rules are considered: total acceptance (TA), acceptance based on the present and future workload (PFW), presented by Nandi 2000, and due date negotiation (DDN) presented by Moreira and Alves 2006. The TA acceptance mechanism is used as a benchmark. The PFW rule works as follows: if the arriving order will not cause the workload limit to be exceeded it is accepted; otherwise it is rejected. The sole purpose of this rule is to keep the total shop load under control rather than allowing it to grow without limit. The DDN mechanism takes into account three types of information: (i) the total workload of jobs in-process plus jobs waiting in the pre-shop pool, (ii) a predefined tolerance of the workload limit, and (iii) the order's due date.

The DDN rule works as follows: when an order arrives, the total workload on the shop (due to the jobs waiting to be released and the jobs already on the shop floor) is computed. If it is lower than a pre-defined limit, the order is immediately accepted. However, if the total workload exceeds that limit, two situations may occur: the negotiation of the due date or the rejection of the order. Negotiation exists whenever the pre-defined limit is surpassed by no more than a certain percentage (the negotiation margin). In this case, a delay in the order's delivery date is proposed. If the customer accepts the new delivery date, the order is put in the accepted orders file. If the customer rejects the new delivery date or if there is no negotiation, the order is rejected. The idea 


\subsection{Due date decision}

The decision about the due date assignment is made simultaneously with the acceptance decision. Only one rule is considered because, by varying the planning factor, it is possible to convert one rule into another. The total work content (TWK) rule defines the due date by adding a certain amount of time, representative of the time that the job will need to be completed, to the order's arrival date:

$$
\mathrm{DD}_{\mathrm{i}}=\mathrm{AD}_{\mathrm{i}}+\mathrm{k}_{\mathrm{TwK}} \times \mathrm{P}_{\mathrm{i}}, \quad \text { where: } \quad \mathrm{DD}_{\mathrm{i}} \text { : due date of job } \mathrm{i} \text {; }
$$

$\mathrm{AD}_{\mathrm{i}}$ : job i arrival date;

$\mathrm{P}_{\mathrm{i}}$ : processing time of job $\mathrm{i}$;

$\mathrm{k}_{\mathrm{TWK}}$ : planning factor.

\subsection{Order release decision}

After being accepted, orders may be released to the shop floor at any time. The order release mechanism determines when and what job in the pre shop pool should be released. Several rules have been studied and proposed in the literature, from very simple (like the immediate release) to sophisticated ones (e.g., backward infinite 
loading). In this study, four order release rules are considered: immediate release (IMR), backward infinite loading (BIL), modified infinite loading (MIL) and planed inputoutput control (PIOC). The IMR release rule is used as a benchmark: as soon as an order is accepted it is released to the shop floor. The BIL mechanism consists in deducting from the due date the expected job flow time. The MIL rule was proposed by Ragatz and Mabert 1984; it is similar to the BIL rule (because it ignores the shop capacity), but it has more information to predict the job flow time since it includes a planning factor about the actual work on shop. MIL determines the release date as follows:

$\mathrm{RD}_{\mathrm{i}}=\mathrm{DD}_{\mathrm{i}}-\mathrm{k}_{1 \mathrm{MIL}} \times \mathrm{n}_{\mathrm{i}}-\mathrm{k}_{2 \mathrm{MIL}} \times \mathrm{Q}_{\mathrm{i}}$, where:

\author{
$\mathrm{RD}_{\mathrm{i}}$ : release date of job $\mathrm{i}$; \\ $\mathrm{DD}_{\mathrm{i}}$ : due date of job $\mathrm{i}$; \\ $\mathrm{n}_{\mathrm{i}}$ : number of operations of job $\mathrm{i}$; \\ $\mathrm{Q}_{\mathrm{i}}$ : number of jobs in queue on job i routing; \\ $\mathrm{k}_{1 \mathrm{MIL}}, \mathrm{k}_{2 \mathrm{MIL}}$ : planning factors.
}

The planed input-output control rule (PIOC) was presented by Moreira and Alves 2005 and includes information about the orders (due date, processing time, number of operations and routing), about the shop floor (workload in all machines) and information related with shop capacity. The central idea of this rule is to control the input, in terms of jobs released to the shop floor, and the output, in terms of shop production capacity, at the same time. 
There is a job release whenever one of the following events occurs: (i) the latest release date (LRD) of an order is reached, or (ii) the workload (corresponding to the jobs in the queue) of any station goes below a pre-defined lower limit.

In the first case, the job that has that date is released. If several jobs have the same LRD, the job that has the earliest due date is selected; if there is still a tie, the job with the largest processing time is chosen. The latest release date is computed in the following way:

$$
\mathrm{LRD}_{\mathrm{i}}=\mathrm{DD}_{\mathrm{i}}-\mathrm{P}_{\mathrm{i}}-\mathrm{k}_{\mathrm{PIOC}} \times \mathrm{n}_{\mathrm{i}} \text {, where: }
$$

$\mathrm{LRD}_{\mathrm{i}}$ : job i latest release date;

$\mathrm{DD}_{\mathrm{i}}$ : due date of job $\mathrm{i}$;

$\mathrm{P}_{\mathrm{i}}$ : processing time of job $\mathrm{i}$;

$\mathrm{n}_{\mathrm{i}}$ : number of operations of job $\mathrm{i}$;

$\mathrm{k}_{\mathrm{PIOC}}$ : planning factor.

In the second trigger mechanism, the job that has its first operation in the station whose queue is below the lower limit is released; if more than one job are tied, the job with the closest LRD is selected; if a tie still exists, the job with the earliest due date is chosen.

The output control is performed by setting an upper limit on the workload corresponding to the jobs in the pre-shop pool and by computing the workload of the shop. If the workload (in the pre-shop pool) is above the defined upper limit, then the short-term capacity is increased by $12.5 \%$. This is obtained by increasing the working time at each machine from eight to nine hours per day. 


\subsection{Dispatching decision}

Once a job is released to the shop floor, its progress through the shop is controlled by the dispatching rule in use. The dispatching rules considered are the first-come-firstserved (FCFS) and the earliest due date (EDD). The FCFS rule does not consider job or shop information in setting priorities, and was selected as a benchmark. The EDD rule uses the job due date information for calculating its priority.

\section{Research methodology}

\subsection{Simulation model}

The simulation model was developed using the software Arena 7.1. (Kelton et al. 2004).

The characteristics of the hypothetical job-shop are identical to those used by Melnyk and Ragatz 1989. The shop consists of six working centres operating forty hours per week. Each working centre contains a single machine and can process only one job at a time. No preemptions are allowed. Job routings are random, with no return visits. The number of operations per order is uniformly distributed between one and six. Order arrivals follow a Poisson process with a mean of one order per hour. The processing time distribution for all six machines is identical: exponential with a mean of 1.5 hours. These characteristics result in a steady state utilization rate of $87.5 \%$ for the shop and for each working centre. 


\subsection{Experimental factors}

In testing the decision rules it is important to assess whether their performance is affected by other factors. Therefore, a full $3 \times 4 \times 4 \times 2$ experimental design was used: the three accept/reject rules described above were simulated in combination with four levels of due date tightness, the four order release rules presented and the two priority dispatching rules considered.

To vary due date tightness, the value of the planning factor $\left(\mathrm{k}_{\mathrm{TwK}}\right)$ in the due date formula described above was set at 4.6, 12.9, 38 and 77.7. These values were selected in such a way that, if the system were operated under the benchmark rules (total acceptance, immediate release and first-come-first-served), the percentage of late jobs would be, approximately, $50 \%, 25 \%, 10 \%$, and $5 \%$. When $\mathrm{k}_{\mathrm{TWK}}=4.6$, the due date is defined in a very tight way, resulting, possibly, in extra pressure on production. At the other extreme, when $\mathrm{k}_{\mathrm{TWK}}=77.7$, the due date becomes too loose, resulting in long lead times. Ragatz and Mabert 1984 used similar levels for the due date parameter, corresponding to tight, medium and loose due dates, resulting in $20 \%, 10 \%$ and $5 \%$ of late jobs, respectively.

\subsection{Performance measures}

In order to assess the impact of the decision rules specific performance criteria must be selected. Nine measures of job-shop performance were considered. These measures are broken down in two categories: 
(i) Due date related performance measures, which are indicative of customer satisfaction and deliverability: mean tardiness, percent tardy, proportion of rejected orders, and mean absolute deviation.

(ii) Workload related performance measures, which are used to evaluate the impact of the load observed on the shop floor: mean waiting time in the pre shop pool, mean time in finished goods inventory, mean queue time on the shop floor, mean total time in the system, and machine utilization.

\subsection{Data collection}

Simulation data were collected with reference to the steady state of the system. In order to remove the effects of the warm-up period, several runs of the simulation model were made to see when the steady state was reached. Performance criteria and utilization levels reached steady state after approximately 4000 working (simulated) hours. However, all statistics were set to zero and restarted after a warm-up period of 10000 simulated hours. Statistics were, then, collected for 90000 hours. Ten replications were performed for each set of experimental conditions. The data collection conditions are the same as those used by Melnyk and Ragatz 1989 and Hendry and Wong 1994, and based on the recommendations of Law and Kelton 2000. 


\section{Main results}

This section discusses the results of the simulation for each of the decision rules considered. Particular attention is paid, for each performance measure, to the best combination of rules.

Tables 1 to 4 contain the simulation results of the due date related performance measures, and Tables 5 to 9 present the results for the workload related performance measures. Each table contains mean values of the ten simulation runs, broken down by the accept/reject rule, the due date tightness, the release procedure, and the dispatch rule.

\section{[Insert Tables 1 to 4 about here]}

The results concerning the mean tardiness are presented in Table 1. It can be seen that, in almost all combinations, the delay decreases as the due date becomes less tight. Moreover, the use of the EDD dispatching rule reduces the value of mean tardiness, regardless of the accept/reject procedure or the order release rule. A decrease in the mean tardiness can also be observed when a mechanism that limits the acceptance of orders (PFW or DDN) is employed. In Table 2 one can notice that an increase in the due date (increase in $\mathrm{k}_{\mathrm{TWK}}$ ), the possibility of rejection (PFW or DDN) and the employment of the EDD rule all lead to a decrease in the proportion of orders delivered after the due date.

As expected, when the TA rule is used, the percentage of rejected orders is $0 \%$ for all combinations of order release mechanisms, dispatching rules and due date tightness 
(see Table 3). The presence of an accept/reject rule does have a significant effect on the percentage of rejected orders. However, this effect could be minimized if its use is combined with the PIOC order release mechanism.

Another important performance measure is the mean absolute deviation, because it determines how far apart are delivery and promised due dates. In Table 4 it can be seen that when due dates are tight the values obtained by using the different order release rules are similar. However, if due dates are loose, the rules BIL and MIL perform better than the PIOC rule.

\section{[Insert Tables 5 to 9 about here]}

The workload measure mean waiting time in the pre-shop pool is affected by the consideration of the accept/reject decision. Given that the acceptance limit is based on the total workload (accepted and not finished), when the work corresponding to the orders waiting in the pre shop pool reaches that limit the new orders are rejected (or placed for negotiation). In Table 5 one can observe that when the PIOC rule is used the time spent in the pre-shop pool is very short. This is explained by the definition of the PIOC mechanism: the release can be triggered by the occurrence of any of two events.

The total time a job is in the system is the sum of the pre-shop pool time, the waiting and processing times at each of the working centres in the job's routing sequence, and the time spent waiting for delivery (as early deliveries are forbidden). It is reported that total time in the system is often long and unreliable almost entirely due to the large proportion of time spent in the queues (Tatsiopoulos and Kingsman 1983, Stalk Jr. and Hout 1992). Therefore, the mean queue time on the shop floor is crucial to 


\section{[Insert Figure 2 and 3 about here]}

From the analysis of the plots one can conclude that EDD is the dispatching rule that has better performance. Actually, it is the best rule in eight out of nine performance measures. In what concerns the decision about accepting or not an incoming order, the best mechanism is the PFW as it is the best rule in six of the nine performance measures. To decide which is the best order release rule, we have to take into consideration the due date tightness and the order release rules simultaneously: when promised due dates are assigned in a loose manner, the BIL and MIL rules are the ones 
that perform better; if tight due dates are set, then the PIOC and IMR mechanisms work better.

\section{Conclusion}

A job-shop is a production process characterized by many different products, manufactured usually in small batches, according to specifications that are generally customer specific.

The main goal of this research was to introduce a multiple decision-making scheme for a general job-shop with the objective of planning and controlling operations, and improving delivery and workload related performance measures

The interactions among the four groups of decisions (accepting or rejecting orders, due date setting, order releasing, and dispatching) and their effects on the measures of performance of the shop (mean tardiness, mean flow time, capacity utilization, etc.) were analysed. From this analysis, it can be concluded that when considering the four types of decision simultaneously, the performance of the job-shop improves, mainly the mean tardiness and the mean total time in the system. Mean tardiness decreases whenever $\mathrm{k}_{\mathrm{TWK}}$ increases, a rejection rule is in use (PFW or DDN) or the EDD dispatching rule is employed. As a result, the percentage of tardy jobs decreases. The time an order spends in the system decreases when the EDD rule is used and when the possibility of rejecting an order exists. If the BIL or MIL rules are used, then the value of the mean earliness is lower, regardless of the $A / R$ rule, dispatching mechanism or due date tightness.

Several directions for future research are: 
a) There can be possible variations of the accept/reject or order release rules presented, taking into consideration other type of information like the orders' urgency/priority or the importance of the customer (based on a Pareto analysis, for instance). Other types of simulation-based rules can be developed and explored.

b) The implementation and analysis of the rules can be extended to more complex manufacturing systems, with more working centres or different layouts. Real-life implementation of these rules is also required to test them in practice.

c) It would be interesting to see how the job-shop performance is sensitive to the decision rules parameters kept constant in this study, such as the rejection limit or the planning parameter used to compute the LRD.

d) Another potential research direction is to explore the interactions among acceptance, due date assignment, order release and dispatching, and their effects on a global performance measure, like total cost.

\section{Acknowledgements}

The authors wish to thank the anonymous referees for providing helpful suggestions. Research supported by FCT Project POCI/EGE/61823/2004. 


\section{References}

Ahmed, I. and Fisher, W., Due date assignment, job order release and sequencing interaction in job shop scheduling. Decision Sciences, 1992, 23 (3), 633-647.

Albin, S., On Poisson approximations for superposition arrival processes in queues. Management Science, 1982, 28 (2), 126-137.

Baker, K., Sequencing rules and due-date assignments in a job-shop. Management Science, 1984, 30 (9), 1093-1104.

Bergamaschi, D., Cigolini, R., Perona, M. and Portioli, A., Order review and release strategies in a job shop environment: a review and classification. International Journal of Production Research, 1997, 35 (2), 399-420.

Bertrand, J., The effects of workload dependent due-date on job shop performance. Management Science, 1983a, 29 (7), 799-816.

Bertrand, J., The use of workload information to control job lateness in controlled and uncontrolled release production systems. Journal of Operations Management, 1983b, 3 (2), 79-92.

Bertrand, J. and Van de Wakker, A., An investigation of order release and flow time allowance policies for assembly job shops. Production Planning and Control, 2002, 13 (7), 639-648.

Bobrowski, P. and Park, P., Work release strategies in a dual resource constrained job shop. Omega - The International Journal of Management Science, 1989, 17 (2), 177-188.

Bulkin, M., Colley, J. and Steinhoff, H., Load forecasting, priority sequencing, and simulation in a job shop system. Management Science, 1966, 13 (2), B29-B51. 
Cigolini, R., Perona, M. and Portioli, A., Comparison of order review and release techniques in a dynamic and uncertain job shop environment. International Journal of Production Research, 1998, 36 (11), 2931-2951.

Conway, R., Priority dispatching and work-in-process inventory in a job shop. Industrial Engineering, 1965, 16 (2), 123-130.

Ebben, M., Hans, E. and Olde Weghuis, F., Workload based order acceptance in job shop environments. OR Spectrum, 2005, 27 (1), 107-122.

Graves, S., A review of production scheduling. Operations Research, 1981, 29 (4), 646675.

Haskose, A., Kingsman B. G. and Worthington, D., Modelling flow and jobbing shops as a queueing network for workload control. International Journal of Production Economics, 2002, 78 (3), 271-285.

Haskose, A., Kingsman B. G. and Worthington, D., Performance analysis of make-toorder manufacturing systems under different workload control regimes. International Journal of Production Economics, 2004, 90 (2), 169-186.

Hendry, L. C. and Kingsman, B. G., Production planning systems and their applicability to make-to-order companies. European Journal of Operational Research, 1989, 40 (1), 1-15.

Hendry, L. C. and Wong, S. K., Alternative order release mechanisms: a comparison by simulation, International Journal of Production Research, 1994, 32 (12), 28272842.

Henrich, P., Land, M. and Gaalman, G., Exploring applicability of workload control concept. International Journal of Production Economics, 2004, 90 (2), 187-198. 
Kelton, W., Sadowski, R. and Sturrock, D., Simulation with Arena, 2004 (McGraw-Hill, $3^{\text {rd }}$ edition, New York).

Kingsman, B. G., Modelling input-output workload control for dynamic capacity planning in production planning systems. International Journal of Production Economics, 2000, 68 (1), 73-93.

Land, M., Parameters and sensitivity in workload control. International Journal of Production Economics, 2006, 104 (2), 625-638.

Land, M. and Gaalman, G., Workload control concepts in job shops: a critical assessment. International Journal of Production Economics, 1996, 46-47 (3), 535548.

Land, M. and Gaalman, G., The performance of workload control concepts in job shops: Improving the release method. International Journal of Production Economics, 1998, 56-57 (3), 347-364.

Law, A. M. and Kelton, W. D., Simulation Modelling and Analysis, 2000 (McGrawHill, $3^{\text {a }}$ edição, New York).

Melnyk, S. and Ragatz, G., Order review/release: research issues and perspectives. International Journal of Production Research, 1989, 27 (7), 1081-1096.

Moodie, D., Demand management: the evaluation of price and due date negotiation strategies using simulation. Production and Operations Management, 1999, 8 (2), $151-162$.

Moodie, D. and Bobrowski, P., Due date demand management: negotiating the trade-off between price and delivery. International Journal of Production Research, 1999, 37 (5), 997-1021. 
Moodie, C. and Roberts, S., Experiments with priority dispatching rules in a parallel processor shop. International Journal of Production Research, 1968, 6 (4), 303-312.

Moreira, M. and Alves, R., A new input-output control order release mechanism: how workload control improves manufacturing operations in a job shop, in 2005 European Simulation and Modelling Conference, 2005, pp. 101-107.

Moreira, M. and Alves, R., Does order negotiation improve the job-shop workload control?, in EurOMA 2006 - The European Operations Management Association Conference - Moving up the Value Chain, 2006, pp. 741-749.

Nandi, A., Input control strategies for make-to-order manufacturing systems via order acceptance/rejection, PhD thesis, University of Calgary, Calgary, Alberta, 2000.

Nandi, A. and Rogers, P., Behaviour of an order release mechanism in a make-to-order manufacturing system with selected order acceptance, in 2003 Winter simulation conference, 2003, pp. 1251-1259.

Oosterman, B., Land, M. and Gaalman, G., The influence of shop characteristics on workload control. International Journal of Production Economics, 2000, 68 (1), 107-119.

Panwalkar, S. and Iskander W., A survey of scheduling rules. Operations Research, 1977, 25 (1), 45-61.

Panwalkar, S., Smith, M. and Seidmann, A., Common due date assignment to minimize total penalty for the one machine scheduling problem. Operations Research, 1982, 30 (2), 391-399.

Philipoom, P. and Fry, T., Capacity-based order review/release strategies to improve manufacturing performance. International Journal of Production Research, 1992, 30 (11), 2559-2572. 
Ragatz, G. and Mabert, V., A simulation analysis of due date assignment rules. Journal of Operations Management, 1984, 5 (1), 27-39.

Ramasesh, R., Dynamic job-shop scheduling: A survey of simulation research. Omega The International Journal of Management Science, 1990, 18 (1), 43-57.

Sabuncuoglu, I. and Karapinar, H. Y., Analysis of order review/release problems in production systems. International Journal of Production Economics, 1999, 62 (3), 259-279.

Sabuncuoglu, I. and Karapinar, H. Y., A load-based and due-date-oriented approach to order review/release in job shops. Decision Sciences, 2000, 31 (2), 413-447.

Seidmann, A. and Smith, M., Due date assignment for production systems. Management Science, 1981, 27 (5), 571-581.

Stalk Jr., G. and Hout, T. M., Competing against time, 1992 (Free Press, New York).

Stevenson, M., Refining a workload control (WLC) concept: a case study. International Journal of Production Research, 2006, 44 (4), 767-790

Stevenson, M. and Hendry, L., Aggregate load-oriented workload control: A review and re-classification of a key approach. International Journal of Production Economics, 2006, 104 (2), 676-693.

Tatsiopoulos, I. P. and Kingsman, B. G., Lead time management. European Journal of Operational Research, 1983, 14 (4), 351-358.

Tsai, C., Chang, G. and Li, R., Integrating order release control with due-date assignment rules. International Journal of Production Research, 1997, 35 (12), 3379-3392.

Vig, M. and Dooley, K., Dynamic rules for due-date assignment. International Journal of Production Research, 1991, 29 (7), 1361-1377. 
Wester, F., Wijngaard, J. and Zijm, W., Order acceptance strategies in a production-toorder environment with setup times and due-dates. International Journal Production Research, 1992, 30 (6), 1313-1326.

Wight, O., Input/output control: a real handle on lead time. Production and Inventory Management Journal, 1970, 11 (3), 9-30.

Wouters, M., Relevant cost information for order acceptance decisions. Production Planning and Control, 1997, 8 (1), 2-9. 
TABLES

Table 1 - Mean tardiness (days)

\begin{tabular}{llrrrrrrrr}
\hline & & \multicolumn{6}{c}{ Dispatching rules } \\
\cline { 3 - 10 } A/R & O/R & \multicolumn{6}{c}{ FCFS } & \multicolumn{5}{c}{ EDD } \\
\cline { 3 - 10 } & D/D & $\mathbf{4 . 6}$ & $\mathbf{1 2 .}$ & $\mathbf{3 8}$ & $\mathbf{7 7 . 7}$ & $\mathbf{4 . 6}$ & $\mathbf{1 2 . 9}$ & $\mathbf{3 8}$ & $\mathbf{7 7 . 7}$ \\
\hline \multirow{3}{*}{ TA } & IMR & 3.8 & 3.7 & 3.6 & 3.5 & 1.9 & 1.1 & 1.1 & 1.1 \\
& BIL & 3.7 & 3.6 & 3.3 & 3.2 & 2.1 & 1.8 & 2.0 & 2.1 \\
& MIL & 3.9 & 4.2 & 3.8 & 3.3 & 2.2 & 1.9 & 2.1 & 2.5 \\
& PIOC & 2.5 & 2.8 & 2.5 & 2.3 & 1.7 & 12 & 2.1 & 3.4 \\
\hline \multirow{3}{*}{ PFW } & IMR & 1.4 & 1.4 & 1.4 & 1.4 & 1.1 & 1.1 & 1.1 & 1.1 \\
& BIL & 1.4 & 1.1 & 0.8 & 0.1 & 1.0 & 1.0 & 0.2 & 0.0 \\
& MIL & 1.3 & 1.0 & 0.4 & 0.1 & 1.0 & 1.0 & 0.3 & 0.0 \\
& PIOC & 1.4 & 1.4 & 1.4 & 1.5 & 1.1 & 1.1 & 1.0 & 2.0 \\
\hline \multirow{3}{*}{ DDN } & IMR & 2.9 & 3.0 & 3.1 & 3.1 & 1.4 & 1.0 & 1.1 & 1.1 \\
& BIL & 2.5 & 1.9 & 1.6 & 1.5 & 1.5 & 1.5 & 1.4 & 1.5 \\
& MIL & 2.5 & 2.0 & 1.7 & 1.7 & 1.5 & 1.5 & 1.5 & 1.6 \\
& PIOC & 2.5 & 3.1 & 2.9 & 2.6 & 1.4 & 1.1 & 1.1 & 2.5 \\
\hline
\end{tabular}

Table 3 - Proportion of rejected orders

\begin{tabular}{|c|c|c|c|c|c|c|c|c|c|}
\hline \multirow{3}{*}{$\mathbf{A} / \mathbf{R}$} & \multirow{3}{*}{$\mathbf{O} / \mathbf{R}$} & \multicolumn{8}{|c|}{ Dispatching rules } \\
\hline & & \multicolumn{4}{|c|}{ FCFS } & \multicolumn{4}{|c|}{ EDD } \\
\hline & & 4.6 & 12.9 & 38 & $\mathbf{7 7 . 7}$ & 4.6 & 12.9 & 38 & 77.7 \\
\hline \multirow{4}{*}{ TA } & IMR & 0.00 & 0.00 & 0.00 & 0.00 & 0.00 & 0.00 & 0.00 & 0.00 \\
\hline & BIL & 0.00 & 0.00 & 0.00 & 0.00 & 0.00 & 0.00 & 0.00 & 0.00 \\
\hline & MIL & 0.00 & 0.00 & 0.00 & 0.00 & 0.00 & 0.00 & 0.00 & 0.00 \\
\hline & PIOC & 0.00 & 0.00 & 0.00 & 0.00 & 0.00 & 0.00 & 0.00 & 0.00 \\
\hline \multirow{4}{*}{ PFW } & $\begin{array}{l}\text { IMR } \\
\end{array}$ & 0.05 & 0.05 & 0.05 & 0.05 & 0.05 & 0.05 & 0.05 & 0.05 \\
\hline & BIL & 0.06 & 0.22 & 0.47 & 0.60 & 0.07 & 0.22 & 0.47 & 0.60 \\
\hline & MIL & 0.07 & 0.25 & 0.49 & 0.61 & 0.08 & 0.25 & 0.49 & 0.61 \\
\hline & PIOC & 0.05 & 0.05 & 0.05 & 0.05 & 0.06 & 0.06 & 0.06 & 0.05 \\
\hline \multirow{4}{*}{ DDN } & IMR & 0.06 & 0.03 & 0.01 & 0.01 & 0.07 & 0.03 & 0.01 & 0.01 \\
\hline & BIL & 0.14 & 0.21 & 0.33 & 0.35 & 0.18 & 0.23 & 0.33 & 0.35 \\
\hline & MIL & 0.17 & 0.25 & 0.34 & 0.36 & 0.20 & 0.26 & 0.34 & 0.36 \\
\hline & PIOC & 0.03 & 0.01 & 0.01 & 0.00 & 0.07 & 0.03 & 0.01 & 0.01 \\
\hline
\end{tabular}

Table 2 - Percentage of tardy jobs

\begin{tabular}{|c|c|c|c|c|c|c|c|c|c|}
\hline \multirow{3}{*}{$\mathbf{A} / \mathbf{R}$} & \multirow{3}{*}{$\mathbf{O} / \mathbf{R}$} & \multicolumn{8}{|c|}{ Dispatching rules } \\
\hline & & \multicolumn{4}{|c|}{ FCFS } & \multicolumn{4}{|c|}{ EDD } \\
\hline & & 4.6 & 12.9 & 38 & 77.7 & 4.6 & 12.9 & 38 & 77.7 \\
\hline \multirow{4}{*}{ TA } & IMR & 0.52 & 0.26 & 0.10 & 0.05 & 0.14 & 0.01 & 0.00 & 0.00 \\
\hline & BIL & 0.52 & 0.27 & 0.13 & 0.08 & 0.20 & 0.03 & 0.02 & 0.01 \\
\hline & MIL & 0.52 & 0.30 & 0.15 & 0.09 & 0.24 & 0.05 & 0.03 & 0.03 \\
\hline & $\mathrm{PIOC}$ & 0.36 & 0.13 & 0.05 & 0.03 & 0.02 & 0.00 & 0.00 & 0.01 \\
\hline \multirow{4}{*}{ PFW } & IMR & 0.17 & 0.06 & 0.02 & 0.01 & 0.01 & 0.00 & 0.00 & 0.00 \\
\hline & BIL & 0.14 & 0.01 & 0.00 & 0.00 & 0.01 & 0.00 & 0.00 & 0.00 \\
\hline & MIL & 0.12 & 0.00 & 0.00 & 0.00 & 0.01 & 0.00 & 0.00 & 0.00 \\
\hline & $\mathrm{PIOC}$ & 0.17 & 0.06 & 0.02 & 0.01 & 0.01 & 0.00 & 0.00 & 0.00 \\
\hline \multirow{4}{*}{ DDN } & IMR & 0.46 & 0.24 & 0.10 & 0.05 & 0.06 & 0.00 & 0.00 & 0.00 \\
\hline & BIL & 0.35 & 0.07 & 0.01 & 0.01 & 0.05 & 0.00 & 0.00 & 0.00 \\
\hline & MIL & 0.33 & 0.07 & 0.02 & 0.01 & 0.05 & 0.00 & 0.00 & 0.00 \\
\hline & PIOC & 0.37 & 0.16 & 0.06 & 0.03 & 0.06 & 0.00 & 0.00 & 0.00 \\
\hline
\end{tabular}

Table 4 - Mean absolute deviation (days)

\begin{tabular}{llrrrrrrrr}
\hline & & \multicolumn{6}{c}{ DCFS } \\
\cline { 3 - 9 } A/R & O/R & \multicolumn{6}{c}{ EDD } \\
\cline { 3 - 9 } & & $\mathbf{D} / \mathbf{D . 6}$ & $\mathbf{1 2 . 9}$ & $\mathbf{3 8}$ & $\mathbf{7 7 . 7}$ & $\mathbf{4 . 6}$ & $\mathbf{1 2 . 9}$ & $\mathbf{3 8}$ & $\mathbf{7 7 . 7}$ \\
\hline \multirow{3}{*}{ TA } & IMR & 2.8 & 6.2 & 21.5 & 47.2 & 1.3 & 6.6 & 23.0 & 49.0 \\
& BIL & 2.7 & 3.7 & 5.0 & 5.5 & 1.3 & 3.3 & 4.9 & 5.5 \\
& MIL & 2.8 & 3.6 & 4.5 & 4.9 & 1.4 & 2.8 & 4.1 & 4.7 \\
& PIOC & 2.1 & 6.4 & 21.6 & 46.5 & 1.7 & 6.4 & 20.8 & 43.5 \\
\hline \multirow{4}{*}{ PFW } & IMR & 1.8 & 6.3 & 20.8 & 43.9 & 1.9 & 6.6 & 21.1 & 44.2 \\
& BIL & 1.7 & 4.2 & 5.7 & 6.3 & 1.8 & 4.2 & 5.7 & 6.3 \\
& MIL & 1.7 & 3.7 & 4.9 & 5.4 & 1.8 & 3.8 & 4.9 & 5.4 \\
& PIOC & 1.8 & 6.3 & 20.8 & 43.6 & 1.9 & 6.6 & 21.1 & 43.9 \\
\hline \multirow{4}{*}{ DDN } & IMR & 5.5 & 7.5 & 22.2 & 47.5 & 5.0 & 8.3 & 23.8 & 49.5 \\
& BIL & 2.1 & 4.3 & 6.8 & 6.9 & 1.7 & 4.7 & 6.8 & 6.9 \\
& MIL & 2.0 & 3.9 & 5.4 & 5.5 & 1.6 & 4.2 & 5.4 & 5.4 \\
& PIOC & 4.4 & 7.5 & 22.7 & 48.2 & 4.9 & 8.2 & 23.7 & 49.5 \\
\hline
\end{tabular}


Table 5 - Mean waiting time in pre shop pool (days)

\begin{tabular}{|c|c|c|c|c|c|c|c|c|c|}
\hline \multirow{3}{*}{$\mathbf{A} / \mathbf{R}$} & \multirow{3}{*}{$\begin{array}{l}\text { O/R } \\
\text { D/D }\end{array}$} & \multicolumn{8}{|c|}{ Dispatching rules } \\
\hline & & \multicolumn{4}{|c|}{ FCFS } & \multicolumn{4}{|c|}{ EDD } \\
\hline & & 4.6 & 12.9 & 38 & 77.7 & 4.6 & 12.9 & 38 & 77.7 \\
\hline \multirow{4}{*}{ TA } & IMR & 0.00 & 0.00 & 0.00 & 0.00 & 0.00 & 0.00 & 0.00 & 0.00 \\
\hline & BIL & 0.11 & 2.59 & 16.6 & 41.8 & 0.11 & 2.60 & 16.6 & 41.7 \\
\hline & MIL & 0.14 & 2.74 & 16.9 & 42.2 & 0.17 & 2.98 & 17.3 & 42.5 \\
\hline & PIOC & 0.16 & 0.39 & 0.25 & 0.26 & 0.02 & 0.00 & 0.02 & 0.09 \\
\hline \multirow{4}{*}{ PFW } & IMR & 0.00 & 0.00 & 0.00 & 0.00 & 0.00 & 0.00 & 0.00 & 0.00 \\
\hline & $\mathrm{BIL}$ & 0.05 & 0.91 & 3.87 & 8.09 & 0.05 & 0.91 & 3.88 & 8.10 \\
\hline & MIL & 0.10 & 1.13 & 4.33 & 8.73 & 0.10 & 1.13 & 4.34 & 8.73 \\
\hline & PIOC & 0.00 & 0.01 & 0.01 & 0.06 & 0.00 & 0.00 & 0.00 & 0.02 \\
\hline \multirow{4}{*}{ DDN } & IMR & 0.00 & 0.00 & 0.00 & 0.00 & 0.00 & 0.00 & 0.00 & 0.00 \\
\hline & BIL & 6.01 & 11.3 & 34.3 & 72.9 & 7.41 & 12.6 & 34.2 & 72.8 \\
\hline & MIL & 7.11 & 13.8 & 35.8 & 75.1 & 8.18 & 14.4 & 36.0 & 75.0 \\
\hline & PIOC & 0.21 & 0.56 & 0.34 & 0.36 & 0.01 & 0.01 & 0.00 & 0.03 \\
\hline
\end{tabular}

Table 7 - Mean waiting time in fg inventory (days)

\begin{tabular}{|c|c|c|c|c|c|c|c|c|c|}
\hline \multirow{3}{*}{$\mathbf{A} / \mathbf{R}$} & \multirow{3}{*}{$\mathbf{O} / \mathbf{R}$} & \multicolumn{8}{|c|}{ Dispatching rules } \\
\hline & & \multicolumn{4}{|c|}{ FCFS } & \multicolumn{3}{|c|}{ EDD } & \multirow[b]{2}{*}{77.7} \\
\hline & & 4.6 & 12.9 & 38 & 77.7 & 4.6 & 12.9 & 38 & \\
\hline \multirow{4}{*}{ TA } & IMR & 2.8 & 8.3 & 24.8 & 50.9 & 1.8 & 7.1 & 23.7 & 49.7 \\
\hline & BIL & 2.5 & 4.5 & 5.6 & 6.0 & 1.7 & 3.7 & 5.2 & 5.7 \\
\hline & MIL & 2.4 & 4.0 & 5.1 & 5.4 & 1.7 & 3.2 & 4.4 & 4.9 \\
\hline & PIOC & 2.9 & 8.0 & 23.8 & 48.8 & 2.1 & 6.9 & 21.4 & 44.1 \\
\hline \multirow{4}{*}{ PFW } & IMR & 2.7 & 7.5 & 22.1 & 45.3 & 2.3 & 7.1 & 21.6 & 51.8 \\
\hline & BIL & 2.5 & 4.5 & 5.8 & 6.4 & 2.2 & 4.5 & 5.8 & 6.4 \\
\hline & MIL & 2.4 & 4.0 & 5.0 & 5.5 & 2.1 & 4.0 & 5.0 & 5.5 \\
\hline & PIOC & 2.7 & 7.5 & 22.0 & 44.8 & 2.3 & 7.1 & 21.6 & 44.5 \\
\hline \multirow{4}{*}{ DDN } & IMR & 11.5 & 10.3 & 25.4 & 51.0 & 7.1 & 8.8 & 24.3 & 50.0 \\
\hline & BIL & 2.8 & 4.9 & 7.0 & 7.0 & 2.0 & 4.8 & 6.9 & 7.0 \\
\hline & MIL & 2.6 & 4.4 & 5.6 & 5.7 & 2.0 & 4.3 & 5.5 & 5.5 \\
\hline & PIOC & 8.3 & 9.6 & 25.1 & 50.7 & 7.0 & 8.8 & 24.2 & 50.0 \\
\hline
\end{tabular}

Table 9 - Machine utilization

\begin{tabular}{|c|c|c|c|c|c|c|c|c|c|}
\hline \multirow{3}{*}{$\mathbf{A} / \mathbf{R}$} & \multirow{3}{*}{$\begin{array}{l}\text { O/R } \\
\text { D/D }\end{array}$} & \multicolumn{8}{|c|}{ Dispatching rules } \\
\hline & & \multicolumn{4}{|c|}{ FCFS } & \multicolumn{4}{|c|}{ EDD } \\
\hline & & 4.6 & 12.9 & 38 & 77.7 & 4.6 & 12.9 & 38 & 77.7 \\
\hline \multirow{4}{*}{ TA } & IMR & 0.87 & 0.87 & 0.87 & 0.87 & 0.87 & 0.88 & 0.88 & 0.88 \\
\hline & BIL & 0.88 & 0.87 & 0.87 & 0.8 & & 0.88 & 0.88 & 0.87 \\
\hline & MIL & 0.87 & 0.88 & 0.88 & 0.8 & 0.87 & 0.87 & 0.88 & 0.87 \\
\hline & PIOC & 0.85 & 0.83 & 0.84 & 0.84 & 0.77 & 0.77 & 0.77 & 0.77 \\
\hline \multirow{4}{*}{ PFW } & IMR & 0.74 & 0.74 & 0.74 & 0.74 & 0.73 & 0.73 & 0.73 & 0.73 \\
\hline & BIL & 0.71 & 0.43 & 0.18 & 0.10 & 0.70 & 0.43 & 0.18 & 0.10 \\
\hline & MIL & 0.69 & 0.39 & 0.16 & 0.09 & 0.68 & 0.39 & 0.16 & 0.09 \\
\hline & PIOC & 0.74 & 0.74 & 0.74 & 0.73 & 0.73 & 0.73 & 0.73 & 0.73 \\
\hline \multirow{4}{*}{ DDN } & IMR & 0.87 & 0.87 & 0.87 & 0.87 & 0.86 & 0.87 & 0.87 & 0.87 \\
\hline & BIL & 0.85 & 0.84 & 0.82 & 0.81 & 0.84 & 0.84 & 0.82 & 0.81 \\
\hline & $\mathrm{MIL}$ & 0.84 & 0.84 & 0.81 & 0.81 & 0.83 & 0.83 & 0.82 & 0.81 \\
\hline & PIOC & 0.87 & 0.87 & 0.88 & 0.87 & 0.86 & 0.87 & 0.88 & 0.88 \\
\hline
\end{tabular}

Table 6 - Mean queue time on shop floor (days)

\begin{tabular}{|c|c|c|c|c|c|c|c|c|c|}
\hline \multirow{3}{*}{$\mathbf{A} / \mathbf{R}$} & \multirow{3}{*}{$\begin{array}{l}\text { O/R } \\
\text { D/D }\end{array}$} & \multicolumn{8}{|c|}{ Dispatching rules } \\
\hline & & \multicolumn{4}{|c|}{ FCFS } & \multicolumn{4}{|c|}{ EDD } \\
\hline & & 4.6 & 12.9 & 38 & 77.7 & 4.6 & 12.9 & 38 & 77.7 \\
\hline \multirow{4}{*}{ TA } & IMR & 3.93 & 3.93 & 3.93 & 3.93 & 2.04 & 1.74 & 1.72 & 1.70 \\
\hline & BIL & 3.87 & 3.93 & 3.90 & 3.92 & 2.29 & 2.54 & 3.17 & 3.39 \\
\hline & MIL & 4.03 & 4.44 & 4.37 & 4.14 & 2.42 & 2.67 & 3.38 & 3.59 \\
\hline & PIOC & 2.29 & 1.84 & 2.08 & 2.11 & 0.95 & 0.95 & 0.93 & 0.90 \\
\hline \multirow{4}{*}{ PFW } & IMR & 1.25 & 1.25 & 1.25 & 1.25 & 0.77 & 0.76 & 0.77 & 0.77 \\
\hline & BIL & 1.11 & 0.31 & 0.06 & 0.03 & 0.71 & 0.25 & 0.06 & 0.02 \\
\hline & MIL & 1.01 & 0.25 & 0.05 & 0.02 & 0.65 & 0.21 & 0.05 & 0.02 \\
\hline & PIOC & 1.25 & 1.24 & 1.23 & 1.17 & 0.77 & 0.76 & 0.76 & 0.75 \\
\hline \multirow{4}{*}{ DDN } & IMR & 3.37 & 3.71 & 3.88 & 3.88 & 2.18 & 1.93 & 1.77 & 1.72 \\
\hline & BIL & 2.85 & 2.86 & 2.67 & 2.61 & 1.84 & 2.27 & 2.60 & 2.54 \\
\hline & MIL & 2.76 & 2.88 & 2.65 & 2.59 & 1.80 & 2.35 & 2.61 & 2.56 \\
\hline & PIOC & 2.47 & 2.27 & 2.65 & 2.57 & 2.13 & 1.90 & 1.77 & 1.65 \\
\hline
\end{tabular}

Table 8 - Mean total time in the system (days)

\begin{tabular}{|c|c|c|c|c|c|c|c|c|c|}
\hline \multirow{3}{*}{$\mathbf{A} / \mathbf{R}$} & \multirow{3}{*}{$\begin{array}{l}\text { O/R } \\
\text { D/D }\end{array}$} & \multicolumn{8}{|c|}{ Dispatching rules } \\
\hline & & \multicolumn{4}{|c|}{ FCFS } & \multicolumn{4}{|c|}{ EDD } \\
\hline & & 4.6 & 12.9 & 38 & 77.7 & 4.6 & 12.9 & 38 & 77.7 \\
\hline \multirow{4}{*}{ TA } & IMR & 7.4 & 12.9 & 29.4 & 55.4 & 4.5 & 9.5 & 26.0 & 52.0 \\
\hline & BIL & 7.2 & 11.6 & 26.9 & 52.5 & 4.8 & 9.5 & 25.7 & 51.6 \\
\hline & MIL & 7.2 & 11.9 & 27.1 & 52.5 & 4.9 & 9.5 & 25.8 & 51.6 \\
\hline & PIOC & 6.0 & 10.9 & 26.7 & 51.8 & 3.7 & 8.4 & 22.9 & 45.7 \\
\hline \multirow{4}{*}{ PFW } & IMR & 4.5 & 9.3 & 24.0 & 47.1 & 3.6 & 8.4 & 23.0 & 13.1 \\
\hline & BIL & 4.3 & 6.2 & 10.0 & 14.7 & 3.5 & 6.1 & 10.0 & 14.7 \\
\hline & MIL & 4.1 & 5.8 & 9.7 & 14.4 & 3.5 & 5.7 & 9.7 & 14.4 \\
\hline & PIOC & 4.5 & 9.3 & 23.9 & 46.6 & 3.6 & 8.4 & 23.0 & 45.8 \\
\hline \multirow{4}{*}{ DDN } & IMR & 15.6 & 14.7 & 29.9 & 55.5 & 9.9 & 11.4 & 26.7 & 52.4 \\
\hline & BIL & 12.4 & 20.0 & 44.9 & 83.6 & 12.1 & 20.6 & 44.6 & 83.3 \\
\hline & MIL & 13.3 & 21.9 & 45.0 & 84.3 & 12.7 & 21.9 & 45.0 & 84.0 \\
\hline & PIOC & 11.7 & 13.1 & 28.8 & 54.3 & 9.8 & 11.3 & 26.7 & 52.4 \\
\hline
\end{tabular}




\section{FIGURES}

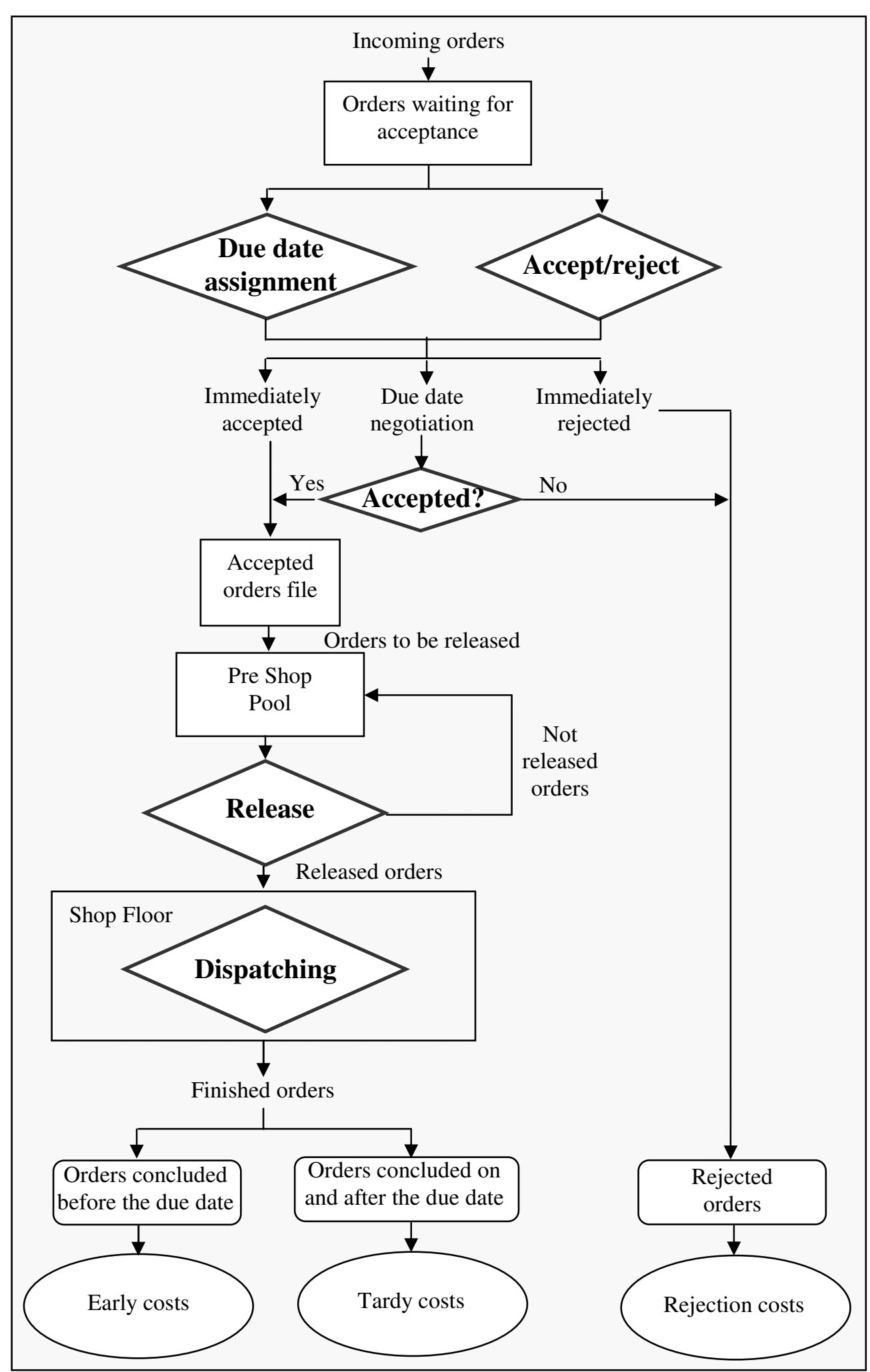

Figure 1- Multiple decision-making scheme. 


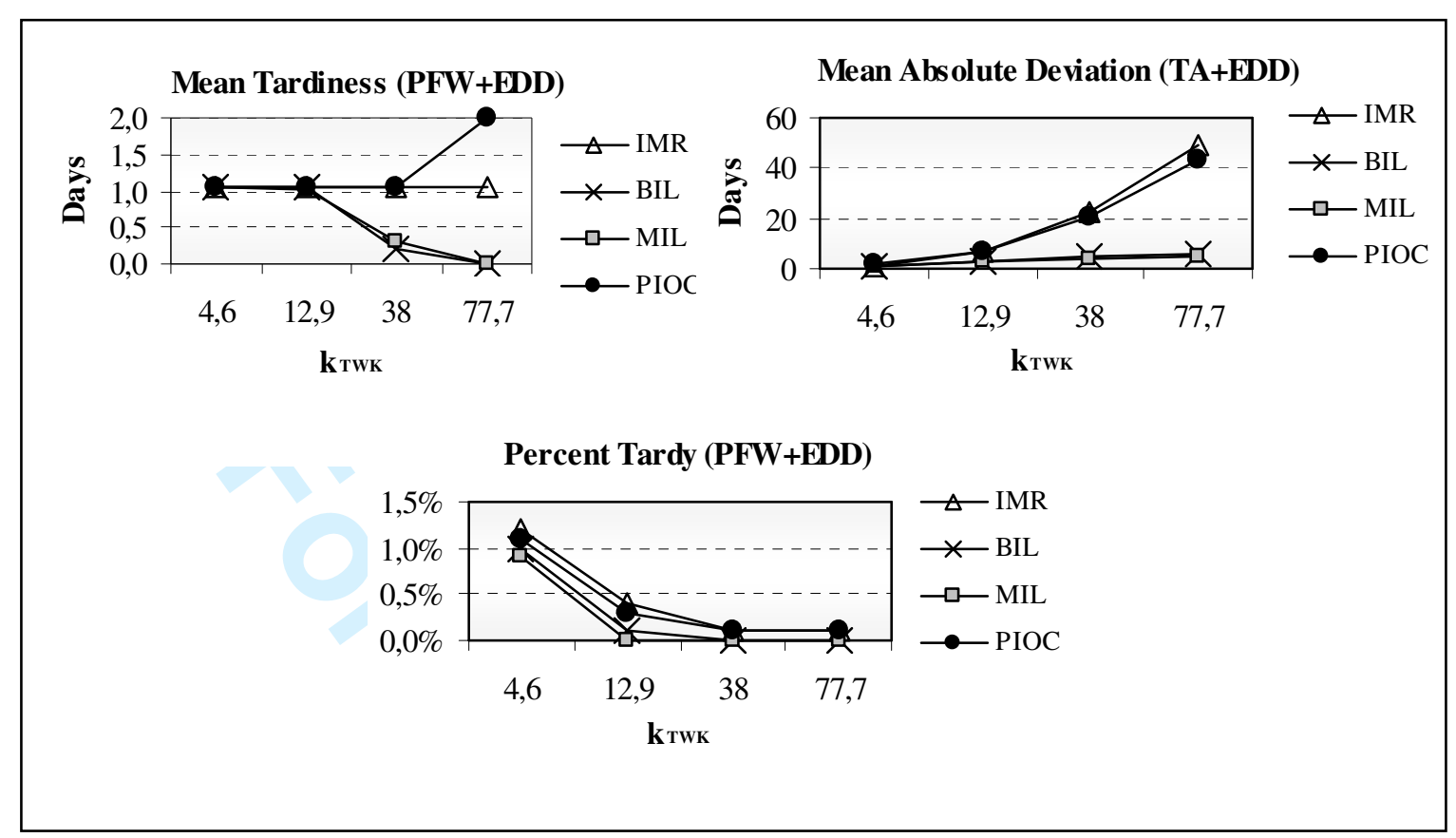

Figure 2- Delivery performance measures in the best combination of decision rules. 


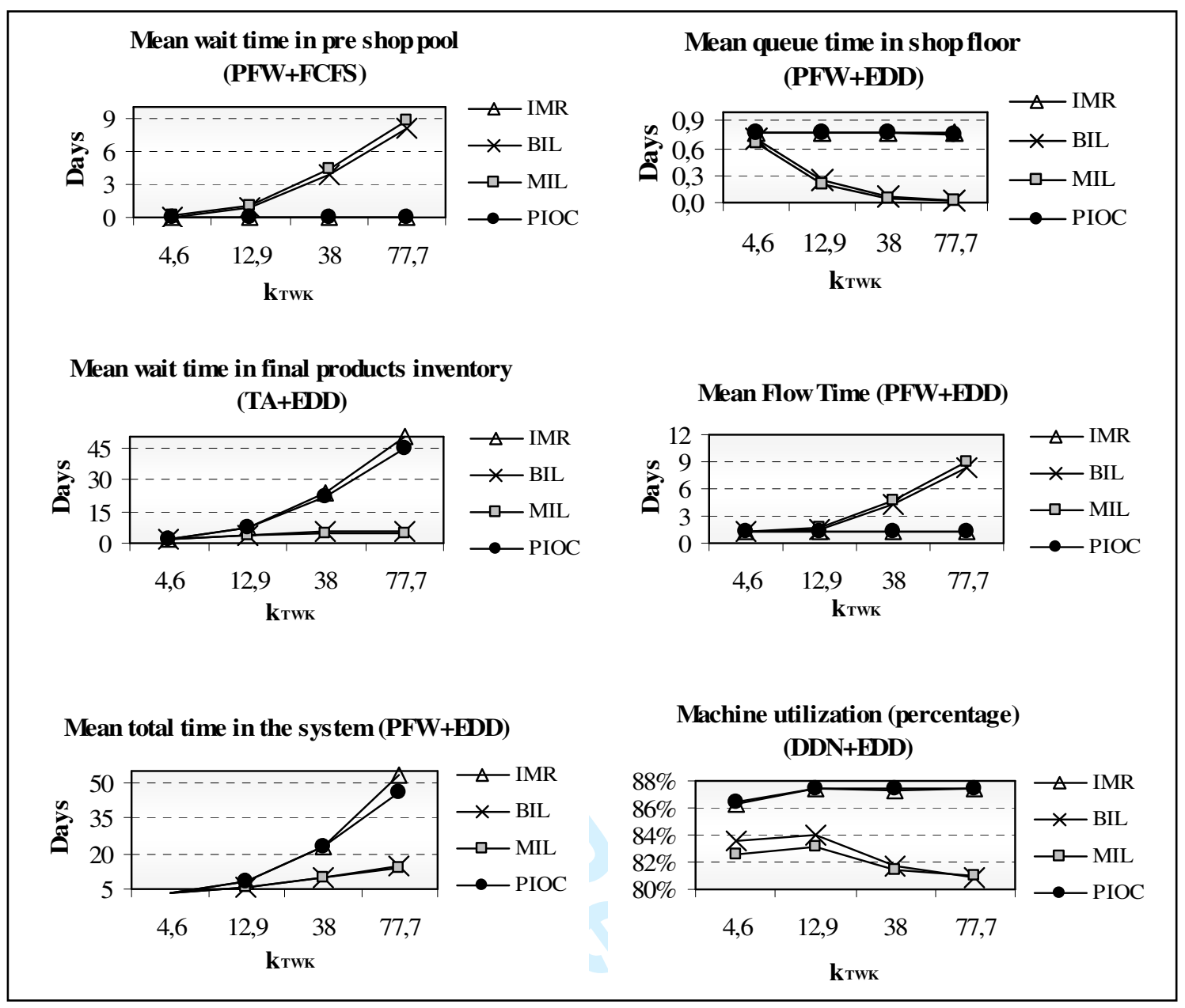

Figure 3- Workload performance measures in the best combination of decision rules. 